\title{
FATIGUE THRESHOLDS OF CRACKS RESULTING FROM IMPACT DAMAGE TO $\gamma$-TiAl
}

\author{
T.S. Harding ${ }^{1}$ and J.W. Jones ${ }^{2}$ \\ ${ }^{1}$ Industrial and Manufacturing Engineering and Business Department, Kettering University, \\ Flint, MI 48504-4898 \\ ${ }^{2}$ Department of Materials Science and Engineering, University of Michigan, \\ Ann Arbor, MI 48109-2136
}

Keywords: Intermetallic; Impact; Fatigue; High temperature

\section{Introduction}

Significant research has been conducted in recent years on the $\gamma$-based titanium aluminide alloys. The low density of $\gamma$-TiAl relative to current nickel-based superalloys, has made it an attractive candidate for use in the low-pressure turbine blades of gas turbine engines [1]. In addition to weight savings, the lower density leads to higher specific stiffness and good high temperature strength retention $[1,2,3]$. However, the ordered crystal structure, typical of intermetallics, leads to inherently low room temperature ductility and fracture toughness. This raises serious concerns about the ability of this material to resist the formation of cracks at impact damage sites, cracks that could subsequently grow in fatigue and lead to failure of the turbine blade. Of particular concern are cracks, which are perhaps too small to be detected, but may still grow under high cycle fatigue conditions.

For large cracks, a long-crack fatigue crack growth threshold $\left(\Delta \mathrm{K}_{\mathrm{TH}}\right)$ is an appropriate design criterion to ensure infinite fatigue life. However, in the case of very small damage levels on the order of a few equiaxed gamma grains or less, $\Delta \mathrm{K}_{\mathrm{TH}}$ fails to accurately portray the threshold for crack propagation $[4,5,6]$. For a fine grained duplex microstructure, the sub-threshold growth of small cracks can be collapsed with long-crack data by using the closure corrected $\Delta \mathrm{K}_{\text {eff }}$ stress intensity to define the crack tip driving force. Small cracks are generally dormant at stress intensities below $\Delta \mathrm{K}_{\mathrm{eff}, \mathrm{TH}}$. However, experiments on a coarse lamellar microstructure suggested that scatter in the small crack threshold was still observed despite correction for closure due to statistical sampling of the larger lamellar colonies [7]. Consequently, the relative size of the dominant microstructural feature can be crucially important in determining the relevant fatigue threshold stress intensity range.

The present study investigates the change in fatigue crack threshold with the size of cracks resulting from simulated impact damage in a duplex $\gamma$-TiAl alloy tested at $600^{\circ} \mathrm{C}$. This work is part of a larger effort to support the transition of $\gamma$-TiAl to industrially relevant gas turbine engine applications.

\section{Materials and Experimental Procedure}

The $\gamma$-TiAl alloy examined in the present study had a nominal composition of Ti-47.9Al-2.0 Cr-1.9Nb (at.\%) and is referred to as "48-2-2." Plates were investment cast followed by an initial heat treatment 


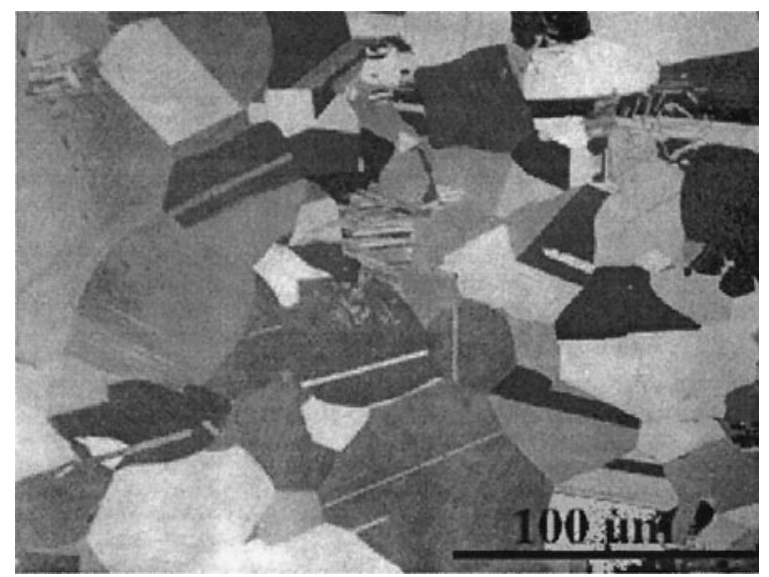

Figure 1. Optical micrograph of the duplex Ti-47.9Al-2.0Cr-1.9Nb alloy showing 70 $\mu$ m equiaxed $\gamma$ grains and a small fraction of lamellar $\left(\gamma-\alpha_{2}\right)$ colonies.

of $5 \mathrm{~h}$ at $1093^{\circ} \mathrm{C}$. The plates were then hot isostatically pressed for $4 \mathrm{~h}$ at $1205^{\circ} \mathrm{C}$ under $172 \mathrm{MPa}$ pressure. This processing step was then followed by a final heat treatment of $2 \mathrm{~h}$ at $1205^{\circ} \mathrm{C}$ and a rapid cool. The processing led to the duplex microstructure shown in Figure 1. The average grain diameter of the equiaxed $\gamma(\mathrm{TiAl})$ grains was approximately $70 \mu \mathrm{m}$. The smaller lamellar colonies, consisting of alternating plates of $\gamma$ and $\alpha_{2}\left(\mathrm{Ti}_{3} \mathrm{Al}\right)$, constituted roughly 6 vol.\% of the overall microstructure. The $\alpha_{2}$ phase was also located along $\gamma$ grain boundaries. The total volume fraction of the $\alpha_{2}$ phase present was about 13 vol.\%. All dogbone shaped fatigue specimens were electro-discharge machined from the cast plates and low stress ground to the desired nominal dimensions of $136 \mathrm{~mm}$ in length with a $3 \mathrm{~mm} \times$ $6 \mathrm{~mm}$ gage section. Each specimen was then hand polished and electropolished to a mirror finish in a perchloric acid solution.

Impact damage was intended to simulate potential shop floor damage to a low-pressure $\gamma$-TiAl turbine blade. Though the variety of real damage of this type would be extensive, the focus of this study is on damage introduced by indenting the $3 \mathrm{~mm}$ edge of the specimens with a hardened steel wedge. Indenting was conducted using a screw-driven mechanical testing machine instrumented with a load cell and data acquisition system.

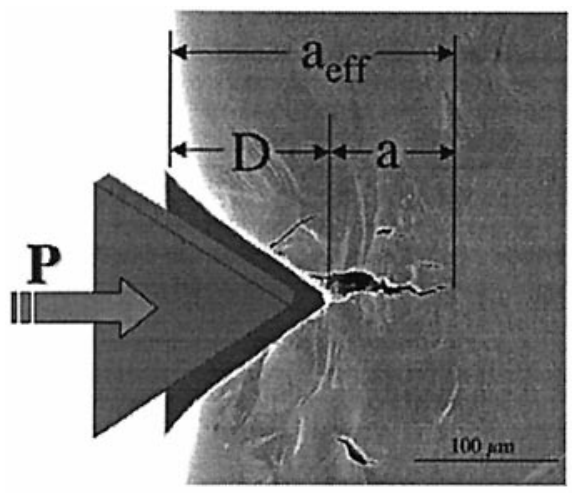

Figure 2. Typical impact damage zone showing the definition of the various damage parameters. 
Figure 2 shows a typical damage zone and the different damage parameters associated with it. The wedge is indented into the specimen such that the maximum load measured by the load cell reaches a peak load, $\mathrm{P}$. This results in the formation of an indent with depth, $\mathrm{D}$, and tip radius, $\rho$. The tip radius is consistently on the order of $10-30 \mu \mathrm{m}$, which means that the indent can effectively be treated as a sharp notch [8]. The indent depth varies linearly with the peak impact load. If the indent depth exceeds a critical value, a crack will form at the tip of the indent with surface length, a. The effective crack length, $a_{\text {eff }}$, is defined here to be the sum of the indent depth and the indent tip crack length. The assumption is that the indent tip crack is through-thickness with a uniform crack front. This is, of course, an oversimplification but still appears to provide a reasonably accurate model of the damage $[9,10]$.

Small crack behavior was examined by comparing the stress-lifetime response of specimens with varying degrees of simulated impact damage with long-crack fatigue crack growth rate data. Standard constant amplitude stress-lifetime tests were conducted on two sets of damaged specimens. One set was impacted at a peak impact load of $3000 \mathrm{~N}$ producing effective crack lengths on the order of 500$600 \mu \mathrm{m}$, while a second set was impacted at $1000 \mathrm{~N}$ producing effective crack lengths on the order of $75 \mu \mathrm{m}$. All tests were carried out at $600^{\circ} \mathrm{C}$ on a servohydraulic testing system at a frequency of $20 \mathrm{~Hz}$ and load ratio of 0.1 .

\section{Results and Discussion}

Previous research on the effects of impact damage on the fatigue properties of the 48-2-2 alloy [9,10] has revealed that for specimens with effective crack lengths on the order of one or two equiaxed $\gamma$ grain diameters, the fatigue strength is less than both the endurance limit and a prediction based upon the long-crack threshold stress intensity. A likely explanation for this behavior is that as the effective crack length diminishes the threshold stress intensity range is steadily decreasing, as demonstrated by Kitagawa and Takahashi [11]. This behavior is attributed to sub-threshold crack growth frequently observed for small cracks $[7,12,13]$. This small crack behavior occurs primarily through a loss of crack closure or through a sampling of only a few individual grains. In the former case, the appropriate threshold becomes the closure corrected, effective threshold stress intensity range $\left(\Delta \mathrm{K}_{\mathrm{eff}, \mathrm{TH}}\right)$. However, in the latter case, the growth of cracks on the order of the microstructural scale are dependent on non-continuum, microstructural factors frequently leading to growth at stress intensities below $\Delta \mathrm{K}_{\text {eff,TH }}$ [7,14]. Here the role of small cracks resulting from impact damage in $\gamma$-TiAl is examined in terms of their effect on the applicable fatigue threshold. The analysis suggests that in the case of low severity damage a threshold below $\Delta \mathrm{K}_{\mathrm{eff}, \mathrm{TH}}$ may be necessary for a threshold-based design approach.

\section{Constant Amplitude S-N Tests}

Figure 3 shows the results of the constant amplitude, stress-lifetime fatigue tests on specimens of the 48-2-2 alloy damaged at peak impact loads of $1000 \mathrm{~N}$ and $3000 \mathrm{~N}$. The variation in fatigue strength with lifetime exhibits a "go-no go" relationship between finite lifetimes and run-out at $10^{7}$ cycles for both sets of specimens. This means that with a small increase in stress the fatigue lifetime can drop from essentially infinite life to less than $10^{5}$ cycles. Such behavior has been reported for undamaged specimens of other $\gamma$-TiAl alloys by Dolley, et al. and Trail and Bowen, $[15,16]$ and is a result of the small difference between the threshold stress intensity and apparent toughness. Figure 3 also demonstrates that impact damage can lead to a significant decrease in fatigue strength. The $10^{5}$-cycle fatigue strength of undamaged 48-2-2, assumed to be a reasonable approximation of the endurance limit, was found to be $320 \mathrm{MPa}$ using the step-test method in previous work [10]. In comparison, specimens 


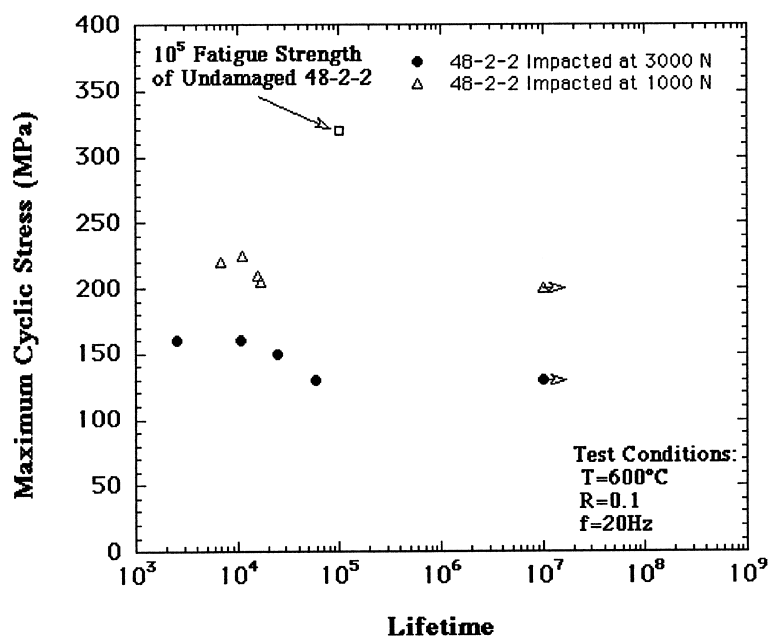

Figure 3. Results of constant amplitude stress-lifetime fatigue tests at $600^{\circ} \mathrm{C}$ on the duplex $48-2-2$ alloy following impacts of $1000 \mathrm{~N}$ and $3000 \mathrm{~N}$.

impacted at a peak load of $3000 \mathrm{~N}$ had an endurance limit of only $130 \mathrm{MPa}$, as determined from standard constant amplitude tests. Likewise, indents of $1000 \mathrm{~N}$ resulted in a measured endurance limit of 200MPa. The fact that such small cracks can lead to large reductions in fatigue strength reinforces the need for a small crack threshold as a lower bound for design of $\gamma$-TiAl components.

\section{$\underline{\text { Modeling of S-N Behavior }}$}

Examination of the change in fatigue crack growth threshold with effective crack length was accomplished by modeling the stress-lifetime curves shown in Figure 3 with a numerically integrated curve fit of the long-crack fatigue crack growth rate data for $48-2-2$ at $600^{\circ} \mathrm{C}$. The governing curve fit equation is referred to as the ATANH equation [17], and is of the form:

$$
\log (d a / d N)=C_{1} \arctan h\left\{C_{2}\left[\log (\Delta K)+C_{3}\right]\right\}+C_{4}
$$

where $\mathrm{C} 1$ to $\mathrm{C} 4$ are constants dependent on the material and test conditions and determined by regression of the fatigue crack growth rate data. Figure 4(a) shows the regression curve fit of the fatigue crack growth rate data, which accurately portrays the near-threshold fatigue crack growth rate behavior of the duplex 48-2-2 alloy. Figure 4(b) shows the stress-lifetime curves generated by numerically integrating equation (1). Effective crack lengths of 400, 500 and $600 \mu \mathrm{m}$ were chosen as the initial flaw sizes, since they bound the measured crack lengths. Agreement between the generated S-N curves and the data indicates that where cracks from impact damage of this type are at least on the order of $500-600 \mu \mathrm{m}$ in length, long-crack fatigue behavior can be anticipated. Therefore, the endurance limits of specimens with cracks of this size are governed by a long-crack $\Delta \mathrm{K}_{\mathrm{TH}}$. Residual stresses located within the damage zone have been neglected in this model. However, the agreement between the data and the ATANH equation suggests that residual stresses may not be as important as first thought.

Modeling of the stress-lifetime response of specimens impacted at $1000 \mathrm{~N}$ using the curve fit shown in Figure 4 resulted in considerable overestimates of the endurance limit. A curve fit of the closure corrected, fatigue crack growth rate data is shown in Figure $5(\mathrm{a})$, where $\Delta \mathrm{K}_{\text {eff,TH }}=4.9 \mathrm{MPa} \vee \mathrm{m}$. However, numerical integration of this regression still led to overprediction of the stress-lifetime response of these lightly damaged specimens as shown in Figure 5(b). When the curve fit was 

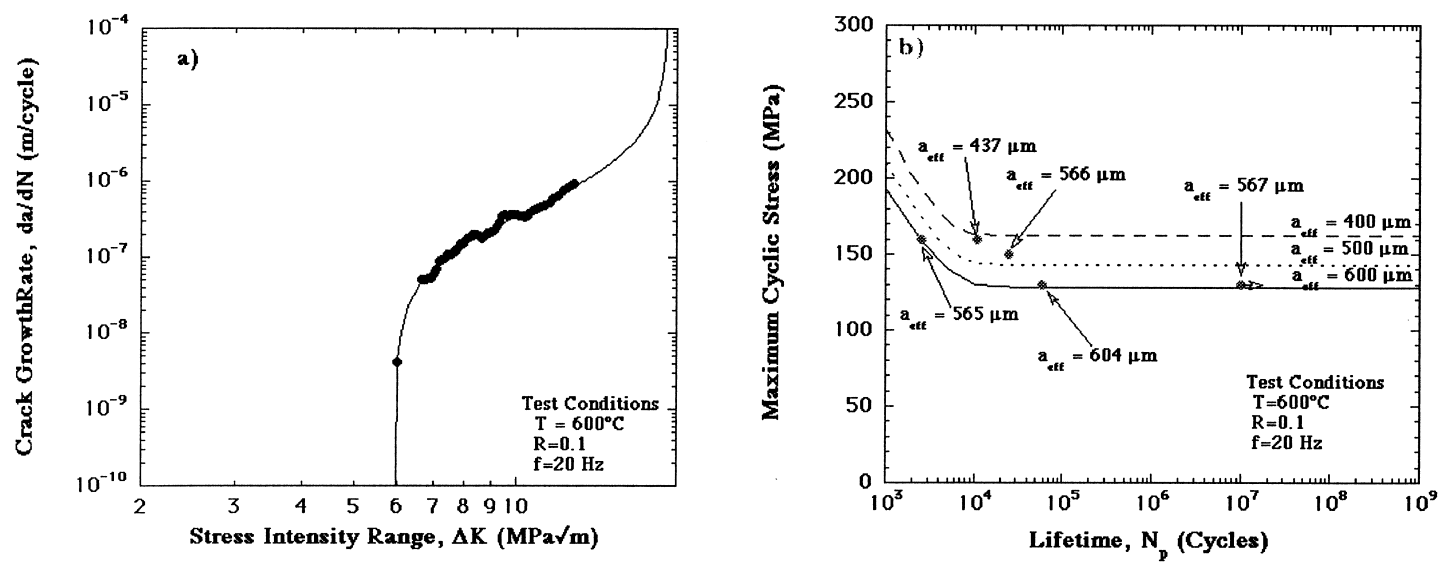

Figure 4. (a)Regression curve fit of the long-crack fatigue crack growth rate data for duplex $48-2-2$ at $600^{\circ} \mathrm{C}$. (b) Comparison of the measured S-N data for specimens damaged at 3000N with curves generated using the ATANH equation. Initial effective crack lengths of each specimen are shown for comparison.

artificially constrained to a threshold of $3.3 \mathrm{MPa} \vee \mathrm{m}$, though, the resulting stress-lifetime curve accurately predicted the endurance limit of these small crack specimens as shown in Figure 5(b). In addition, the behavior at shorter lifetimes is also closely predicted by the curve fit with constrained threshold. These results indicate that for cracks roughly equal to a single $\gamma$ grain diameter in length $\Delta \mathrm{K}_{\mathrm{eff}, \mathrm{TH}}$ is an inappropriate fatigue threshold, and that a more conservative small-crack threshold may be required for design. In addition, the fact that modified closure corrected, crack growth rate data can be used to predict the behavior of these microstructurally small cracks at finite lifetimes suggests that these cracks may quickly grow to a size where they are sampling several grains.

It should be pointed out that the threshold stress intensity of $3.3 \mathrm{MPa} \vee \mathrm{m}$ was arbitrarily chosen to produce the best fit of the data shown in Figure 3 for specimens impacted at 1000N. However, Yokoshima and Yamaguchi [18] identified this value as the lower limit of the fracture toughness of
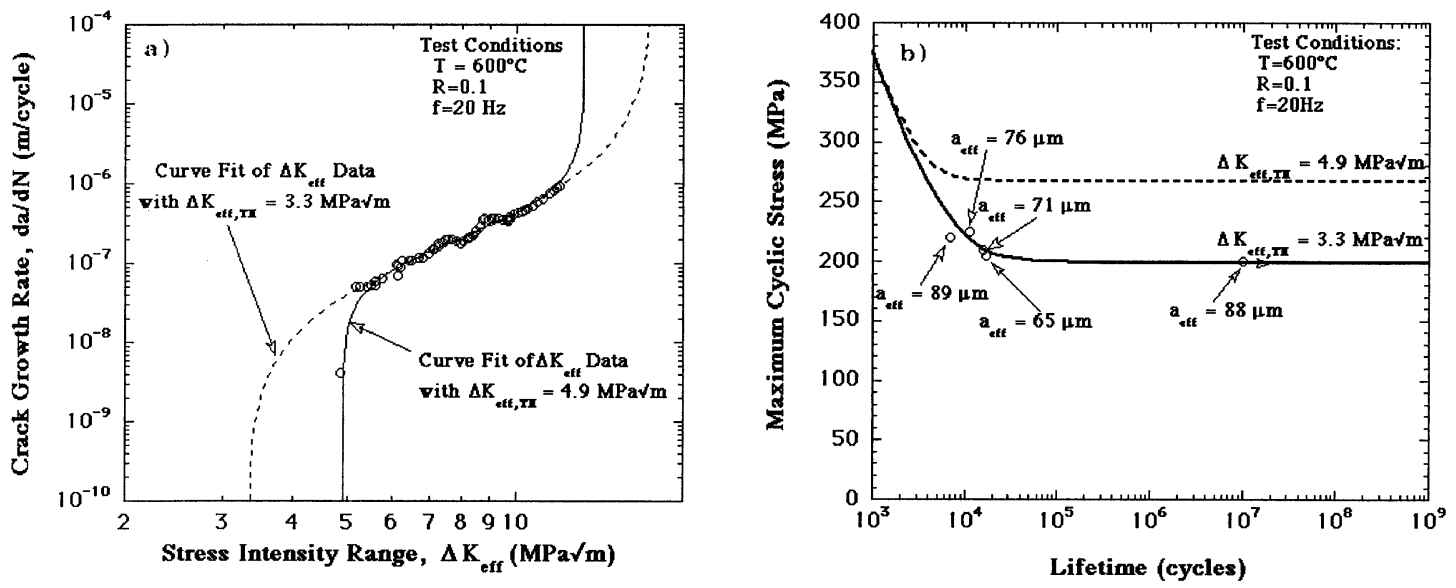

Figure 5. (a) Data regression of the closure corrected, long-crack fatigue crack growth rate data of $48-2-2$ at $600^{\circ} \mathrm{C}$. A fit of the original data with $\Delta \mathrm{K}_{\text {eff, } \mathrm{TH}}=4.9 \mathrm{MPa} \vee \mathrm{m}$ is shown along with a fit artificially constrained to have a threshold of $3.3 \mathrm{MPa} \vee \mathrm{m}$. (b) Comparison of the stress-lifetime curves generated using the ATANH equation with measured data. Use of the lower threshold value results in good estimation of the stress-lifetime response of specimens with effective crack lengths on the scale of $75 \mu \mathrm{m}$. 
polysynthetically twinned (PST) crystals of a lamellar $\gamma$-TiAl when the lamellar plates are oriented perpendicular to the loading axis. This correlation may be purely coincidental. However, it points to the necessity for a more complete understanding of the effects of local microstructural features on the threshold stress intensity of cracks resulting from low severity impacts.

\section{Conclusions}

Based on an experimental study of the change in the stress-lifetime response for long and small cracks in a duplex Ti-47.9Al-2.0 Cr-1.9Nb alloy damaged by the method examined here, the following conclusions can be made:

1) The stress-lifetime behavior exhibits a strong "go-no go" relationship regardless of the level of damage introduced. This suggests that even small changes in the applied stress can lead to a decrease in lifetime of two orders of magnitude.

2) Cracks on the order of $75 \mu \mathrm{m}$, or roughly one $\gamma$ grain diameter, lead to a reduction of the $600^{\circ} \mathrm{C}$ endurance limit of the alloy examined from 320MPa to 200MPa.

3) Modeling of the stress-lifetime response of severely damaged specimens using long-crack fatigue crack growth rate data indicates that for cracks at least $500-600 \mu \mathrm{m}$ in length, long crack behavior can be anticipated. This further suggests that the use of $\Delta \mathrm{K}_{\mathrm{TH}}$ as a design constraint may be appropriate where cracks of this size are expected.

4) For cracks roughly on the scale of the microstructural unit size, use of the long-crack $\Delta \mathrm{K}_{\mathrm{TH}}$ or $\Delta \mathrm{K}_{\mathrm{eff}, \mathrm{TH}}$ to model the endurance limit proved invalid. Instead, an arbitrarily chosen "microstructurally small crack threshold" was needed. Furthermore, the stress-lifetime response at shorter lifetimes was still accurately modeled using closure corrected fatigue crack growth rate data. This suggests that once these microstructurally small cracks begin growing they quickly become physically small cracks.

5) Local microstructure likely plays an important role in determining the threshold of these microstructurally small cracks, and as such requires further investigation.

\section{$\underline{\text { Acknowledgments }}$}

Funding for this work was provided by the Air Force Office of Scientific Research under grant F49620-95-1-0359. The valuable contributions of Drs. James Larsen and Andrew Rosenberger of Wright Patterson Air Force Base are gratefully acknowledged. The authors would also like to thank Mr. Volus McKenna of Carnegie Mellon University for conducting the impact tests.

\section{$\underline{\text { References }}$}

1. C. M. Austin and T. Kelly, in Structural Intermetallics, ed. Darolia et al., p. 465, TMS, Warrendale, PA (1995).

2. Y-W. Kim, J. Metals. 41(7), 24 (1989).

3. S. C. Huang and J. C. Chessnutt, in Intermetallic Compounds, vol. 2: Practice, ed. J. H. Westbrook and R. L. Fleischer, pp. 73-90, John Wiley and Sons, New York (1994).

4. J. P. Campbell, J. J. Kruzic, S. Lillibridge, K. T. Venkataswara Rao, and R. O. Ritchie, Scripta Mater. $37(5)$, 707 (1997).

5. K. S. Chan and D. S. Shih, Metall. Trans. 28A, 79 (1997).

6. K. S. Chan and D. S. Shih, Metall. Trans. 29A, 73 (1998).

7. J. J. Kruzic, J. P. Campbell, and R. O. Ritchie, Acta Mater. 47(3), 801 (1999).

8. R. A. Smith and K. J. Miller, Int. J. Mech. Sci. 20(10), 201 (1978).

9. T. S. Harding, J. W. Jones, P. S. Steif, and T. M. Pollock, Scripta Mater. 40(4), 445 (1999). 
10. T. S. Harding and J. W. Jones, Scripta Mater. accepted for publication.

11. H. Kitagawa and S. Takahashi, in Proceedings of the 2nd International Conference on Mechanical Behavior of Metals, p. 627, Boston (1976).

12. J. P. Campbell, A. L. McKelvey, S. Lillibridge, K. T. Venkateswara Rao, and R. O. Ritchie, in Deformation and Fracture of Ordered Intermetallic Materials III, ed. Sobojeyo et al., p. 141, TMS, Warrendale, PA (1996).

13. S. Suresh, Fatigue of Materials, p. 291, Cambridge University Press, Cambridge, UK (1991).

14. R. O. Ritchie, in Small Fatigue Cracks: Mechanics, Mechanisms and Applications, ed. Ravichandran, Ritchie, and Murakami, p. 233, Elsevier Science, London (1999).

15. E. J. Dolley, N. E. Ashbaugh, and B. D. Worth, in Fatigue '96: Proceedings of the 6th International Fatigue Congress, vol. III, ed. Lutjering and Nowack, p. 1755, Elsevier Ltd., London (1996).

16. S. J. Trail and P. Bowen, Mater. Sci. Eng. 192/193, 427 (1995).

17. J. M. Larsen, B. D. Worth, C. G. Annis Jr., and F. K. Haake, Int. J. Fract. 80, 237 (1996).

18. S. Yokoshima and M. Yamaguchi, Acta Mater. 44(3), 873 (1996). 